\title{
Psoriasis and uveitis: a literature review*
}

\author{
Psoríase e uveíte: uma revisão da literatura
}

\author{
Naiara Abreu de Azevedo Fraga ${ }^{1}$ \\ Ivonise Follador ${ }^{3}$ \\ Vitória Regina Rêgo ${ }^{5}$
}

\author{
Maria de Fátima Paim de Oliveira ${ }^{2}$ \\ Bruno de Oliveira Rocha ${ }^{4}$
}

\begin{abstract}
Psoriasis is a systemic, chronic, immunologically mediated disease, with significant genetic and environmental influences. It affects from 1 to $3 \%$ of the world population. Recently, the relation between psoriasis and different comorbidities, particularly metabolic syndrome, has become extremely relevant. Uveitis is characterized by a process of intraocular inflammation resulting from various causes. Considering psoriasis and uveitis as immune-mediated diseases, this study aims to evaluate the possible association of psoriasis and/or psoriatic arthritis with uveitis and its subtypes. Few studies have evaluated the association of uveitis and psoriasis without joint involvement. It seems that psoriasis without arthropathy is not a risk factor for the development of uveitis. Uveitis tends to develop more frequently in patients with arthropathy or pustular psoriasis than in patients with other forms of psoriasis. Ophthalmic examination should be performed periodically in patients with psoriasis and uveitis. If ophthalmopathy is diagnosed, the patient should receive adequate treatment with anti-inflammatory drugs or immunomodulators to prevent vision loss.
\end{abstract}

Keywords: Arthritis, psoriatic; Psoriasis; Uveitis

Resumo: Psoríase é uma doença sistêmica, crônica, imunologicamente mediada, com importante influência genética e ambiental, que afeta 1 à $3 \%$ da população mundial. Nos últimos anos, a relação da psoríase com diferentes comorbidades, em especial a síndrome metabólica, tornou-se extremamente relevante. A uveíte é caracterizada por um processo de inflamação intra-ocular resultante de várias causas. Considerando a psoríase e a uveíte como doenças imunologicamente mediadas, o presente trabalho visa avaliar a possível associação da psoríase e/ou artrite psoriática com a uveíte e seus subtipos. Poucos são os estudos que avaliam a associação de uveíte e psoríase sem comprometimento articular. Parece que a psoríase sem artropatia não seria um fator de risco para desenvolvimento de uveíte. A uveíte tende a desenvolver mais frequentemente em pacientes com artropatia ou psoríase pustulosa que em outras formas de psoríase. Avaliação oftalmológica deve ser feita periodicamente em pacientes com psoríase, proporcionando ao paciente um diagnóstico precoce da oftalmopatia e a instituição de tratamento adequado com anti-inflamatórios não hormonais ou drogas imunomoduladoras, no intuito de evitar a perda da visão nos pacientes com psoríase e uveíte.

Palavras-chave: Artrite psoriásica; Psoríase; Uveíte

Received on 13.12.2011.

Approved by the Advisory Board and accepted for publication on 04.05.2012

* Work conducted at the Service of Dermatology - Hospital Universitário Professor Edgar Santos (Professor Edgar Santos University Hospital) - Federal University of Bahia (HUPES-UFBA) - Salvador (BA), Brazil.

Conflict of interest: None

Financial Support: None

Resident in Dermatology, Federal University of Bahia (UFBA) - Salvador (BA), Brazil.

PhD in Medicine and Public Health - Preceptor of the Service of Dermatology, Federal University of Bahia (UFBA) - Salvador (BA), Brazil

PhD in Medicine and Public Health - Coordinator and preceptor of residency in dermatology, Federal University of Bahia (UFBA) - Salvador (BA), Brazil.

Student of Medicine, Federal University of Bahia (UFBA) - Salvador (BA), Brazil.

M.Sc. in Medicine and Health Sciences - Head and Assistant Professor of the Service of Dermatology, Federal University of Bahia (UFBA) - Salvador (BA), Brazil.

C 2012 by Anais Brasileiros de Dermatologia 


\section{PSORIASIS: A SYSTEMIC INFLAMMATORY DISEASE}

Psoriasis is an organ-specific autoimmune disease triggered by activation of the immune system. This also occurs in other immune-mediated diseases such as Crohn's disease, rheumatoid arthritis, multiple sclerosis, and type- 1 diabetes. ${ }^{1} \mathrm{~T}$ cells and different pro inflammatory cytokines play a major role in the pathogenesis of psoriasis and illustrate how increasing knowledge on immune molecular mechanisms contributes to the development of new therapies. ${ }^{2,3}$

Clinical evidence confirms that psoriasis is not restricted to the skin. Epidemiological studies show that psoriasis is associated with an increased risk of morbidities and mortality. Comorbidities typically associated with psoriasis are psoriatic arthritis, inflammatory bowel disease, psychiatric and psychosocial disorders. Recent studies have shown a high prevalence of cardiovascular comorbidities secondary to metabolic changes associated with psoriasis. These include diabetes, obesity, dyslipidemia, hypertension, and coronary heart disease. Association of psoriasis with other genetic diseases such as Crohn's disease and type II diabetes has also been reported based on epidemiological studies that showed a high frequency of psoriasis in patients with these entities. ${ }^{4,5}$ The transition from normal skin to the fully developed psoriatic lesion is orchestrated by complex interactions between cytokines and chemokynes. Proinflammatory cytokines are responsible for many of the histopathological alterations seen in skin with psoriatic plaques. TNF- $\alpha$ is a key inflammatory cytokine in the immunopathogenesis of psoriasis. It is produced by various cells such as activated T and B cells, NK cells and, in the presence of inflammation, it is primarily synthesized by macrophages in response to multiple proinflammatory stimuli. It is found at high levels in the skin, joints and plasma of patients with psoriasis and is directly associated with disease activity. ${ }^{5}$ Interferongamma (INF- $\Upsilon$ ) and tumor necrosis factor-alpha (TNFa) are able to stimulate the expression of class II MHC molecules and intercellular adhesion molecules (ICAM-1). Vascular endothelial growth factor (VEGF) and TNF- $\alpha$ stimulate angiogenesis. At the same time, interleukin-1 (IL-1) activates mastocytes; granulocytemacrophage colony stimulating factor (GM-CSF) activates neutrophils; nerve growth factor stimulates the growth of cutaneous nerves, and IL-6 and transforming growth factor-alpha (TGF- $\alpha$ ) promote the proliferation of keratinocytes. TNF- $\alpha$, in particular, appears to affect the function of different cell types in the psoriatic skin. ${ }^{2}$ The interaction between cytokines in psoriasis has been described as type-1, which assumes a linear relationship between inductors (IL-23 and IL12), IFN- $\Upsilon$ and TNF- $\alpha$ production by type- 1 T-cells and activation of INF-responsive genes through the transduction of signals and activation of transcription 1 (STAT1). Although this model is conceptually useful, it involves only a fraction of the more than 1300 genes that become upregulated in psoriatic lesions. Cytokines derived from keratinocytes, such as platelet-derived growth factor (PDGF) and VEGF, affect the growth of cells from the stromal support. Activated stromal cells produce an excess of factors such as keratinocyte growth factor (KGF) that induce the proliferation of keratinocytes. Various cytokines originating from the immune system, including IL-1, IL-6, IL17, IL-19, IL-20, TNF and INFs, also induce keratinocyte proliferation. Antagonists of TNF and IL-12 and/or IL-23 cytokines, such as antibodies or fusion proteins, may block the activation of keratinocytes and cytokine production. ${ }^{1}$

The pathogenesis of psoriasis is characterized by activation of $\mathrm{T}$ cells and, consequently, inflammatory cells in the skin, promoting the proliferation of keratinocytes and epidermal hyperplasia. Proinflammatory cytokines are released by TH1 cells, including TNF- $\alpha$, IL-2 and INF, inducing the inflammatory cascade. In the skin, activated keratinocytes produce other cytokines, including IL-6, IL-8 and TGF- $\alpha$ and $\beta$. This process leads to mild persistent inflammation in psoriasis and is common in other inflammatory diseases. The role of the inflammatory process in the pathogenesis of psoriasis supports the use of agents against $\mathrm{T}$ cell activation (efalizumab and alefacept) and those against mediators of the inflammatory cascade such as antiTNF agents (infliximab, etanercept and adalimumab) in the treatment of this dermatosis. ${ }^{6}$

Although rodent models support the important role of T lymphocytes in the pathogenesis of psoriasis, it is clear that these cells trigger the disease only in a susceptible environment, since results are obtained only in the skin of individuals with psoriasis and not in healthy donors. ${ }^{2}$

\section{UVEITIS}

Anatomical classification, clinical manifestations and diagnosis

Uveitis is characterized by an intraocular inflammatory process resulting from various causes. The uvea is the mid-portion of the eye. Its anterior portion includes the iris and the ciliary body, and its posterior portion consists of the choroid. Anterior uveitis or iritis is inflammation of the anterior uveal tract. When the adjacent ciliary body is also affected, the process is known as iridocyclitis. Terms used to describe uveitis occurring behind the crystalline lens of the eye include vitritis, intermediary uveitis, choroiditis, retinitis, chorioretinitis or retinochoroiditis. Anterior uveitis is four times more common than posterior uveitis. 
Individual forms of uveitis may be differentiated as a function of the location of the inflammation within the eye, symmetry and continuity of the inflammation, associated complication and distribution of cells along the corneal endothelium. ${ }^{7,8}$

Symptoms of uveitis depend on the portion of the uveal tract involved. Anterior uveitis may cause pain and redness, although these symptoms are mild and onset is insidious. In such cases, the extent of vision loss varies. In contrast, intermediate and posterior uveitis are painless and do not normally result in red eyes; however, visual alterations such as floaters and a decrease in visual acuity may occur. ${ }^{7}$

The diagnosis of iritis is made with the use of a slit-lamp, with which the anterior segment of the eye can be visualized. Leukocytes are not normally found in the aqueous humor and their presence in the anterior ocular chamber allows a diagnosis of anterior uveitis. Nevertheless, diagnosis of posterior and intermediate uveitis is made by direct visualization of the chorioretinal inflammation and/or detection of leukocytes in the vitreous humor using a slit-lamp together with special lenses that focus on the posterior chamber, or by indirect ophthalmoscopy and manual lenses.

\section{diseases \\ Uveitis and its association with systemic}

Uveitis can be divided into four main subgroups according to the etiology of the inflammation - infectious disease, immune-mediated disease, syndromes limited to the eyes or idiopathic forms. Of the patients with uveitis, around $40 \%$ of cases are secondary to an immune-mediated disease; around 30\% of the cases of uveitis do not fit into any well-defined etiology. Genetic predisposition also contributes to the development of uveitis. There is a strong genetic link between uveitis and a locus on chromosome 9. A study that included a large population of family members with ankylosing spondylitis also confirmed a link between HLA-B27 and uveitis. ${ }^{8,9}$ The main causes of uveitis are summarized in chart 1 .

Infectious causes of uveitis include bacterial infections (syphilis, tuberculosis, bartonellosis), viral infections (cytomegalovirus, herpes simplex, herpes zoster), fungal infections and parasitic infections (congenital toxoplasmosis). These infections have different presentations and affect populations with different risk factors. ${ }^{10}$

Uveitis may occur as a manifestation of various systemic diseases. Spondyloarthropathies such as ankylosing spondylitis and reactive arthritis are the immune-mediated systemic diseases most commonly associated with uveitis in North America and Europe. ${ }^{10,11}$ Around $40 \%$ of the patients with diseases associa- ted with HLA-B27 develop sudden-onset anterior uveitis. When this occurs, uveitis is often the manifestation that suggests diagnosis of the disease. Uveitis associated with spondyloarthritis is twice as common in men as it is in women. It is generally unilateral and tends to resolve spontaneously three months after the onset of symptoms. Recurrences are common and may occur in the contralateral eye. Prognosis for this form of uveitis is generally excellent. Patients with recurrent anterior uveitis with no symptoms of spondyloarthropathies, particularly those who are HLA-B27. positive, may have an incomplete form of spondyloarthropathy. A strong association between patients with recurrent anterior uveitis and the presence of inflammation at sites of insertion of the tendons and ligaments (enthesitis) has been found, as shown by ultrasonography, regardless of the fact that clinical symptoms of spondyloarthropathy are absent. Around $7 \%$ of the patients with psoriatic arthritis and 2-9\% of the patients with inflammatory bowel disease (IBD) may develop uveitis; $45 \%$ of the cases of IBD associated with uveitis are HLA-B27-positive. Unlike uveitis associated with spondyloarthropathies, uveitis associated with IBD and psoriatic arthritis is often bilateral and located behind the crystalline lens. Furthermore, it is often of insidious onset, chronic and is more common in women than in men. Approximately $75 \%$ of the patients with uveitis and IBD also have arthritis, which may be axial and/or peripheral and may mimic spondyloarthropathies. ${ }^{10,12}$

Sarcoidosis is an important cause of uveitis. Approximately $20 \%$ of patients develop ocular symptoms as the initial manifestation of the disease. Uveitis in patients with sarcoidosis may be associated with vasculitis, which may be perivascular or may involve changes in the vasculature of the retina. Around 80\% of the patients with Behçet's disease develop uveitis, which is typically bilateral and is generally the principal manifestation of the disease. If appropriate treatment is not received, it may lead to blindness. Juvenile idiopathic arthritis (JIA) may be associated with uveitis, especially in cases of pauciarticular disease and a positive antinuclear factor. It is more common in children, being generally bilateral, insidious and asymptomatic. Other causes include Kawasaki's disease (mild anterior uveitis), relapsing polychondritis and Sjögren's syndrome; however, less common associations include systemic lupus erythematous and systemic vasculitis (Wegener's granulomatosis). ${ }^{10}$

Vogt-Koyanagi-Harada (VKH) syndrome is the second cause of uveitis in Japan after Behçet's disease. VKH syndrome is an autoimmune disease characterized by bilateral posterior uveitis with an accumulation of liquid beneath the retina, leading to retinal displacement. Patients with this syndrome may develop viti- 
CharT 1: Main systemic causes of uveitis

\begin{tabular}{|ll|}
\hline $\begin{array}{l}\text { Autoimmune } \\
\text { spondyloarthropathies }\end{array}$ & $\begin{array}{l}\text { Ankylosing spondylitis } \\
\text { Reactive arthritis (Reiter's } \\
\text { syndrome) } \\
\text { Psoriasis } \\
\text { Inflammatory bowel disease } \\
\text { Juvenile inflammatory arthritis }\end{array}$ \\
& Bacterial: syphilis, tuberculosis, \\
bartonellosis. & Viral: cytomegalovirus, herpes \\
simplex, herpes zoster. & Fungal \\
& Parasitic: congenital toxoplasmosis. \\
& Sarcoidosis \\
Vogt-Koyanagi-Harada syndrome & Kawasaki's disease \\
Behçet's syndrome \\
Relapsing polychondritis \\
Sjögren's syndrome \\
Systemic lupus erythematosus \\
Systemic vasculitis (Wegener's \\
granulomatosis)
\end{tabular}

ligo, poliosis, aseptic meningitis, alopecia and involvement of the vestibulocochlear nerve. VKH syndrome is strongly associated with HLA class II. ${ }^{13}$

\section{Cytokine profile in uveitis}

Studies suggest that the cytokine profile in the aqueous humor varies in accordance with the etiology of uveitis. El-Asrar et al. analyzed cytokine levels in the aqueous humor of patients with uveitis, measuring the expression of different cytokines in the various clinical types. That study suggests that both Th17 and Th1 immune response are involved in the immunopathogenesis of the disease. IL-17 levels in the aqueous humor of patients with uveitis were found to be higher than those in the control group, correlating significantly with the activity of the disease. IL-17 exerts a proinflammatory effect, inducing the secretion of other proinflammatory cytokines, chemokines, prostaglandin $\mathrm{E} 2$, intercellular adhesion molecule- 1 and metalloproteinases in various tissues and cell types, resulting in the recruitment of neutrophils, monocytes and Th1 cells for target tissues. In addition, IL-17 acts synergically with other cytokines such as IL-1 $\beta$ and TNF- $\alpha$. Elevated levels of IL-17 and INF- $\Upsilon$ in the aqueous humor of patients with Behçet's disease and VKH syndrome and in uveitis associated with HLA-B27 support the involvement of Th1 and Th17 immune response in the immunopathogenesis of endogenous uveitis. ${ }^{14}$
Levels of TNF- $\alpha$, a proinflammatory cytokine that plays a central role in inducing and maintaining inflammation in autoimmune reactions, are also significantly higher in the aqueous humor of patients with uveitis. ${ }^{14,15}$

El-Asrar et al. also showed evidence of an increase in IL-15 in the aqueous humor of patients with Behçet's disease, VKH syndrome and uveitis associated with HLA-B27. IL-15 is a proinflammatory cytokine that activates $\mathrm{T}$ cells and proliferation factors, with a structural homology to IL-2. Both IL-15 and IL2 stimulate the proliferation and activation of $\mathrm{B}$ and $\mathrm{T}$ cells and also maintain the activation of natural killer (NK) cells. IL-15 facilitates the persistence of lymphocytes, which are important in the specific immune response against exogenous pathogens, in addition to inducing the production of inflammatory cytokines such as TNF- $\alpha$ and IL-1 $\beta$. Nevertheless, the uncontrolled expression of IL-15 increases the risk of survival of autoreactive T cells, which lead to the development of autoimmune diseases. ${ }^{14}$

\section{ASSOCIATION BETWEEN PSORIASIS AND UVEITIS}

Psoriasis is a chronic, multifactorial, systemic, inflammatory disease with varying phenotypical expression in terms of distribution and severity. Although there is an association between psoriasis (especially the arthropathic form and psoriasis pustulosa) and intraocular inflammatory disease, particularly uveitis, few studies have evaluated the ophthalmological pathologies that accompany psoriasis vulgaris. ${ }^{1}$ Overall, ophthalmological manifestations occur in about $10 \%$ of the cases of psoriasis and include blepharitis, conjunctivitis, keratitis, xerophthalmia, corneal abscess, cataract, orbital myositis, symblepharon, chorioretinopathy, uveitis and ectropion with trichiasis and madarosis secondary to eyelid involvement. ${ }_{16,17}$ Ajitsaria et al. described a case of orbital myositis in a child with psoriasis and juvenile psoriatic arthritis. ${ }^{17}$ It has recently been proposed that etiological factors may contribute to the development of ocular lesions in patients with mild to moderate psoriasis, ranging from changes in the surface of the conjunctiva to alterations in the lacrimal film and dysfunction of the meibomian gland. ${ }^{16,18}$

Although the etiology of psoriasis and its association with ocular disease remain unknown, it has been suggested that activated neutrophils in peripheral blood may be responsible for the attacks of anterior uveitis associated with psoriatic arthritis. Uveitis tends to develop more often in patients with arthropathy or psoriasis pustulosa rather than the other forms of psoriasis. ${ }^{19}$ Studies suggest that a breakdown in the barrier between the blood and the aqueous humor may occur as a result of a subclinical inflamma- 
tion in patients with psoriasis, even when ocular symptoms are not present. ${ }^{16,18}$

Uveitis is a severe ocular complication that may occur in $7-20 \%$ of the patients with psoriasis. ${ }^{16}$ Chandran et al. conducted a cross-sectional study in which they found a prevalence of uveitis of $2 \%$ in patients with psoriasis irrespective of the severity of the dermatosis. An association between uveitis and chronic plaque psoriasis has also been found, and in these patients uveitis tends to be bilateral, prolonged and more severe. Uveitis patients with psoriasis tend to be older than those without psoriasis. Uveitis, particularly anterior uveitis, has also been associated with the arthropathic form of the disease. ${ }^{18,19}$

Uveitis associated with psoriasis tends to be anterior, bilateral, chronic (mean duration 11.2 weeks), recalcitrant and is more likely to require treatment with non steroidal anti-inflammatory drugs compared to idiopathic forms of uveitis. It is also associated with a greater likelihood of posterior ocular involvement. Episodes of bilateral uveitis occur in $7-21 \%$ of idiopathic cases compared to $56 \%$ of cases of uveitis associated with psoriasis. In cases of psoriatic arthritis, uveitis begins later (at a mean age of 48 years), whereas in idiopathic cases uveitis tends to appear at 3040 years of age. This may occur due to the fact that the prevalence of psoriasis increases with age; therefore, psoriatic uveitis occurs later because psoriasis affects older individuals.

Patients with psoriasis have increased erythrocyte sedimentation rate and high levels of protein $\mathrm{C}$ and $\alpha 2$-macroglobulin. The mechanisms that deliver inflammatory cells to the initial psoriatic lesions are not yet completely understood; however, immune complexes or complement activation mediated by cell surface proteases associated with other chemotactic factors such as leukotriene B4 are found in high levels in the aqueous humor in cases of uveitis in experimental models. Therefore, psoriasis may be considered a systemic disease capable of affecting the skin, joints and eyes. ${ }^{20}$

\section{ASSOCIATION BETWEEN PSORIATIC ARTH- RITIS / SERONEGATIVE SPONDYLOARTHROPAT- HIES, UVEITIS AND HLA-B27}

Psoriatic arthritis belongs to the group of spondyloarthropathies that includes some subgroups for which HLA-B27 is the genetic marker. Seronegative rheumatic diseases such as psoriatic arthritis, reactive arthritis and ankylosing spondylitis have common clinical symptoms, including inflammatory complications of the spine, joints, skin and eyes, and are associated with an increase in the incidence of HLA-B27. Lambert and Wright reported that intraocular inflammation in the form of conjunctivitis and uveitis are fin- dings that are common to seronegative spondyloarthropathies. ${ }^{21}$ In a study conducted with 394 patients evaluated for spondyloarthropathies, 5 were found to have psoriatic arthritis. HLA-B27 was positive in 94\% of the patients. ${ }^{22}$ In psoriatic arthritis, HLA-B27 has been found in $20 \%$ of the cases of peripheral arthritis, reaching $70 \%$ in cases of axial involvement. Psoriatic arthritis is found in 5\% of the cases of guttate psoriasis and in $15 \%$ of the cases of plaque psoriasis. The clinical signs of arthropathy are found around ten years following onset of the skin condition. Around $84 \%$ of HLA-B27-positive patients with anterior uveitis have another disease associated with HLA-B27 such as reactive arthritis, ankylosing spondylitis or psoriatic arthritis. In reactive arthritis, $85 \%$ of patients are HLA-B27positive. In contrast, in psoriatic arthritis, HLA-B27 is positive in only $13-20 \%$ of the cases of peripheral arthritis and in $50-70 \%$ of the cases of sacroiliitis. This explains the greater occurrence of uveitis in reactive arthritis (20-30\%) compared to cases of psoriatic arthritis. The presence of HLA-B27 in psoriasis patients is associated with type II of the disease (late onset psoriasis) and shows a temporal relationship with the development of arthritis. The presence of the B51 gene was associated with the presence of uveitis only in patients with psoriasis. ${ }^{11,19,22,23}$

The association between uveitis and psoriatic arthritis was reported for the first time in 1976 by Lambert and Wright in a study that involved 112 patients, $7.1 \%$ of whom had anterior uveitis. Among these patients with iritis (anterior uveitis), the prevalence of sacroiliitis was $43 \%$, while the prevalence of spondylitis was $28.5 \%$ - higher prevalence rates than those found in patients without iritis. The prevalence of iritis among patients with sacroiliitis was 15\% and among patients with spondylitis, 6\%. HLA typing was performed in 5 patients with iritis and HLA-B27 was positive in 2 patients (40\%). In relation to the patients without iritis, the prevalence of HLA-B27 positivity was $29 \%$ (15/52 cases). Patients with iritis do not differ from the other patients in relation to age at onset or the duration of arthritis. ${ }^{21}$

The relationship between psoriasis, uveitis and HLA-B27 is still not fully established. In a study conducted with 36 patients with uveitis and psoriasis, uveitis was more common and more severe in patients with positivity for HLA-B27. Chandran et al. suggest that the severity of psoriasis is an independent risk factor for the development of uveitis. ${ }^{18}$ The presence of HLA-B27 may be associated with more severe uveitis in patients with psoriasis, more often requiring anti-inflammatory drugs to control the ophthalmopathy compared to patients with uveitis and negativity for HLA-B27. These data suggest that HLA-B27-positive patients have a more resistant form of uveitis that is 
also more recurrent and difficult to control. Furthermore, HLA-B27-positivity may contribute to the earlier onset of psoriasis, arthritis and bilateral sacroiliitis. ${ }^{22}$

Most patients with uveitis and psoriatic arthritis with axial involvement are male and are more likely to be HLA-B27-positive than patients with peripheral psoriatic arthritis. There is axial involvement in about $50 \%$ of the patients with psoriatic arthritis and uveitis. In a series of 112 patients with psoriatic arthritis and uveitis, $50 \%$ of the cases had anterior and unilateral uveitis of sudden onset, which also occurs in patients with spondyloarthropathies. However, this study had certain limitations such as the exclusion of patients with mild to moderate forms of the disease, as well as the failure to investigate the presence of axial disease using imaging tests and to test HLA in the patients studied. ${ }^{13}$

Paiva et al. evaluated 16 patients with uveitis and psoriatic arthritis; 8 of them had peripheral arthritis $(50 \%), 6(37.5 \%)$ had peripheral and axial disease and $2(12.5 \%)$ had only the axial form of the disease.

${ }^{11}$ These patients were retrospectively compared with 89 patients with other types of spondyloarthropathy and uveitis. The patients with psoriasis were diagnosed with uveitis at older ages (at a mean age of 39 years) compared to patients with other spondyloarthropathies (mean 33 years). The diagnosis of uveitis was made at a mean of 9.7 years following the onset of symptoms of psoriatic arthritis. Uveitis associated with psoriatic arthritis followed a more insidious course and was more likely to be continuous, bilateral and to be situated behind the crystalline lens compared to cases of uveitis and spondyloarthropathy. In the cases of arthropathic psoriasis with axial involvement, all the 8 patients were men and of the 6 patients tested for HLA-B27 in this group, all tested positive. In the peripheral arthritis group, 3 patients were tested for HLA-B27 and all were negative. This difference was statistically significant $(\mathrm{p}=0.012)$. Patients with axial disease who developed uveitis were younger than those with only peripheral arthritis (33.6 versus 44.5 years, $\mathrm{p}<0.01)$. Of the patients with axial disease only, all were HLA-B27-positive and developed episodic, sudden-onset, unilateral uveitis such as seen in cases of Reiter's syndrome and ankylosing spondylitis. These findings suggest that male patients with psoriatic arthritis tend to develop uveitis of a pattern similar
ChaRT 2: Factors associated with the presence and/or severity of uveitis in patients with psoriasis

\section{HLA-B27}

Psoriasis pustulosa

Arthropathic psoriasis

Axial arthropathy

Late onset psoriasis (type II)

Being male

HLA- buman leukocyte antigen

to that seen in cases of ankylosing spondylitis; however, female patients tend to develop peripheral arthritis and a pattern of uveitis more typical of that found in inflammatory bowel disease (bilateral involvement, behind the crystalline lens, of insidious onset, chronic). ${ }^{11}$ The main factors associated with the presence and/or severity of uveitis in patients with psoriasis are shown in chart 2 .

\section{CONCLUSION}

Few studies have been conducted to evaluate the association between uveitis and psoriasis when the joints are not affected. Psoriasis without arthropathy does not appear to be a risk factor for the development of uveitis. It is more likely to develop in patients with arthropathy or psoriasis pustulosa compared to other forms of psoriasis. The presence of HLA-B7 may be associated with more severe uveitis in patients with psoriasis, more often requiring treatment with antiinflammatory drugs to control the ophthalmopathy compared to HLA-B27-negative patients with uveitis. These data suggest that HLA-B27-positive patients tend to develop a more resistant, recurrent form of uveitis that is more difficult to control. Ophthalmological evaluation should be carried out periodically in psoriatic patients with ocular symptoms or arthropathy, assuring an early diagnosis of the ophthalmopathy and appropriate treatment with nonsteroidal antiinflammatory drugs or immunomodulators, thus preventing loss of vision in patients with psoriasis and uveitis. Further studies are required to evaluate the association between psoriasis and uveitis, including relationships between the forms of the disease and its severity and the impact of treatment, particularly in this country. 


\section{REFERENCES}

1. Lowes MA, Bowcock AM, Krueger JG, Pathogenesis and therapy for psoriasis. Nature. 2007:445:866-73.

2. Schon MP, Boehncke WH. Psoriasis. N Engl J Med. 2005;352:1899-912.

3. Gulliver W, Long-term prognosis in patients with psoriasis. $\mathrm{Br} \mathrm{J}$ Dermatol. 2008;159 (Suppl 2):2-9

4. Duarte GV, Follador I, Cavalheiro CMA, Silva TS, Oliveira MFP, Psoriasis and obesity: literature review and recommendations for management. An Bras Dermatol. 2010;85:355-60.

5. Lima EA, Lima MA. Imunopatogênese da psoríase: revisando conceitos. An Bras Dermatol. 2011;86:1151-8.

6. Nickoloff BJ, Nestle FO. Recent insights into the immunopathogenesis of psoriasis provide new therapeutic opportunities. J Clin Invest. 2004;113:1664-75.

7. Darrell RW, Wagener HP, Kurland LT. Epidemiology of uveitis. Incidence and prevalence in a small urban community. Arch Ophthalmol. 1962:68:502-14.

8. Rosenbaum JT, Uveitis. An internist's view. Arch Intern Med. 1989;149:1173-6.

9. Martin TM, Zhang G, Luo J, Jin L, Doyle TM, Rajska BM, et al. A locus on chromosome $9 p$ predisposes to a specific disease manifestation, acute anterior uveitis, in ankylosing spondylitis, a genetically complex, multisystem, inflammatory disease. Arthritis Rheum. 2005;52:269-74

10. Rothova A, Buitenhuis HJ, Meenken C, Brinkman CJ, Linssen A, Alberts C, et al. Uveitis and systemic disease. Br J Ophthalmol. 1992;76:137-41.

11. Paiva ES, Macaluso DC, Edwards A, Rosenbaum JT. Characterisation of uveitis in patients with psoriatic arthritis. Ann Rheum Dis. 2000;59:67-70.

12. Lyons JL, Rosenbaum JT. Uveitis associated with inflammatory bowel disease compared with uveitis associated with spondyloarthropathy. Arch Ophthalmol. 1997:115:61-4.

13. Rubsamen PE, Gass JD. Vogt-Koyanagi-Harada syndrome. Clinical course, therapy, and long-term visual outcome. Arch Ophthalmol. 1991;109:682-7.

14. El-Asrar AM, Struyf S, Kangave D, Al-Obeidan SS, Opdenakker G, Geboes K, et al. Cytokine profiles in aqueous humor of patients with different clinical entities of endogenous uveitis. Clin Immunol. 2011;139:177-84.

15. Ooi KG, Galatowicz G, Calder VL, Lightman SL. Cytokines and Chemokines in Uveitis - Is there a Correlation with Clinical Phenotype? Clin Med Res. 2006;4:294-309.
16. Erbagci I, Erbagci Z, Gungor K, Beckir N, Ocular Anterior Segment Pathologies and Tear Film Changes in Patients with Psoriasis Vulgaris. Acta Med Okayama. 2003:57:299-303

17. Ajitsaria R, Fergunson V, Mayout S,Cavanagh N, Psoriasis, psoriatic arthropathy and relapsing orbital myositis. Clin Exp Dermatol. 2001;26:274-5.

18. Chandran NS, Greaves M, Gao F, Lim L, Cheng BC. Psoriasis and the eye: prevalence of eye disease in Singaporean Asian patients with psoriasis. J Dermatol. 2007;34:805-10.

19. Rehal B, Modjtahedi BS, Morse LS, Schwab IR., Maibach HI. Ocular Psoriasis. J Am Acad Dermatol. 2011;65:1202-12.

20. Durrani K, Foster CS, Psoriatic Uveitis: A Distinct Clinical Entity? Am J Ophthalmol. 2005;139:106-11.

21. Lambert JR, Wright V. Eye inflammation in psoriatic arthritis. Ann Rheum Dis 1976;35:354-6.

22. Fernández-Melón J, Muñoz-Fernández S, Hidalgo V, Bonilla-Hernán G, Schlincke A, Fonseca A, et al. Uveitis as the initial clinical manifestation in patients with spondyloarthropathies. J Rheumatol. 2004;31:524-7.

23. Christophers E. Comorbidities in psoriasis. Clin Dermatol. 2007;25:529-34.

How to cite this article: Fraga NAA, Oliveira MFP, Follador I, Rocha BO, Rêgo VR. Psoriasis and uveitis: a literature review. An Bras Dermatol. 2012;87(6):877-83. 